\title{
Severe Outbreak of Surgical Sepsis Due to Staphylococcus aureus of Unusual Type and Origin
}

\author{
RICHARD W. PAYNE,* M.A., M.D., M.C.PATH.
}

Brit. med. F., 1967, 4, 17-20

Outbreaks of staphylococcal infection in hospital due to infection arising in the operating-theatre are probably less rare than reports in the literature would suggest. There are many possible explanations for this natural reticence. However, it is felt that the following outbreak should be recorded since there are a number of features of general interest.

\section{Outbreak in Outline}

The outbreak occurred at St. Albans City Hospital-a 400bedded provincial general hospital-in January 1963. Each surgical ward has for some years maintained a wound infection register and it has been the practice of the clinical pathology department to keep a record of all coagulase-positive staphylococci (Staphylococcus aureus) isolated from patients in the hospital; a record is also kept of the antibiotic sensitivity pattern of each organism. In January 1963 the number of patients from whom Staph. aureus was isolated began to rise (Fig. 1). Nearly all these organisms were resistant to penicillin, streptomycin, and tetracycline when tested by a routine Multodisk diffusion method. This was a pattern of antibiotic resistance that was uncommon in the hospital at the time.

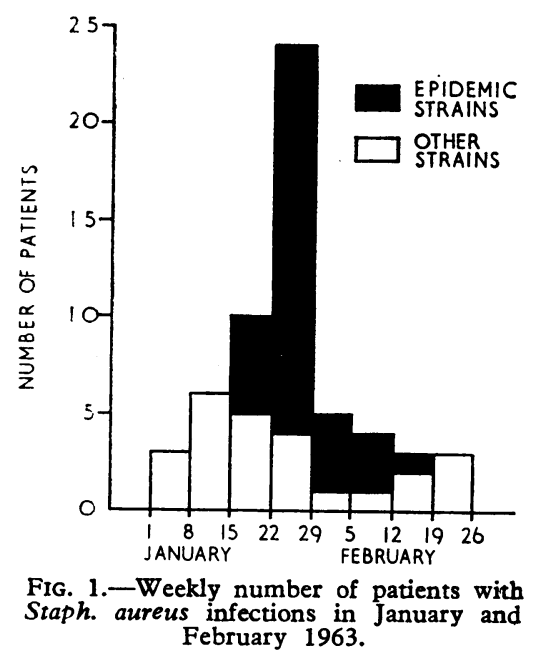

Early in the outbreak it became apparent that all the affected patients had staphylococcal wound infections and that patients in many separate wards were involved. The patients were under the care of six consultant surgeons. It was therefore felt that the most probable source of infection lay in the operating-theatres.

Subsequently, Staph. aureus was shown to be widely distributed throughout the theatre suite. It was also found that an anaesthetist (A) was not only a nasal and skin carrier but also a "disseminator" of Staph. aureus of the same antibiotic-sensitivity pattern as the affected patients.

* Consultant Clinical Pathologist, Mid-Herts Group of Hospitals. Present address, Department of Haematology, The Victoria Infirmary,
The theatres were closed and washed down with hypochlorite solution. This was not effective, so the theatre suite was washed down again much more thoroughly with hypochlorite solution followed by fumigation with formalin vapour and finally shown to be bacteriologically clean.

\section{Organism}

Coagulase-positive staphylococci (Staph. aureus) of two phage patterns were involved in this outbreak: (a) phage type 80 and (b) phage untypable (Holt, 1963). The antibiotic sensitivity patterns of these two different phage types of Staph. aureus were the same, as shown by a Multodisk plate diffusion method (Table I).

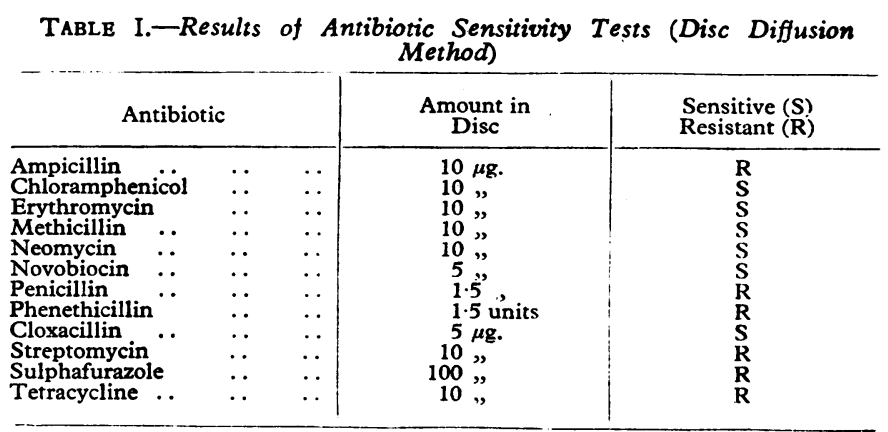

The phage "untypable" strain was further investigated in the Department of Bacteriology at the Leeds School of Medicine. Their report stated "This strain is typical of our yellow isolates. It forms bright yellow pigment on glycerol monoacetate agar, is non-proteolytic, and multiple-resistant (resistant to penicillin, streptomycin, tetracycline, and mercury). It falls into phage group III, subdivision $77 \mathrm{w}$ (1,000 R.T.D.)" (Jacobs, Willis, Ludlam, and Goodburn, 1963 ; Willis, 1963).

\section{Carrier}

Swabs taken from the anterior nares, the dorsum of each hand, and the forehead of the anaesthetist (A.) on 24 January all yielded a heavy growth of Staph. aureus. The organisms had the same antibiotic sensitivity pattern as those isolated from the affected patients (Table I) and were subsequently shown to be of the same phage patterns (phage type 80 and phage untypable).

In retrospect it was discovered that $A$. had been found to be a nasal carrier of Staph. aureus three years previously at another hospital. During the ensuing three years he had been actively associated with clinical work in other hospitals, but had not to his knowledge been associated with an outbreak of staphylococcal infection previously. He had had psoriasis for eight years. In December 1962 he had suffered an acute exacerbation of his skin condition necessitating hospital admission and local and systemic treatment with corticosteroids. This acute exacerbation had settled fairly rapidly, leaving many 
large desquamating but not ovently infected areas of skin. A. returned to his anaesthetic duties on 7 January 1963 and continued to work until 24 January.

Exposure plates were placed on the floor of a room for 20 minutes prior to A.'s entry and then for 20 minutes, during which time $A$. entered the room, removed his clothes, and dressed again at a distance of 10 feet (3 metres) from the plates. The plates exposed while A. undressed and dressed showed a heavy contamination with Staph. aureus (Fig. 2) of the two phage patterns, described above.

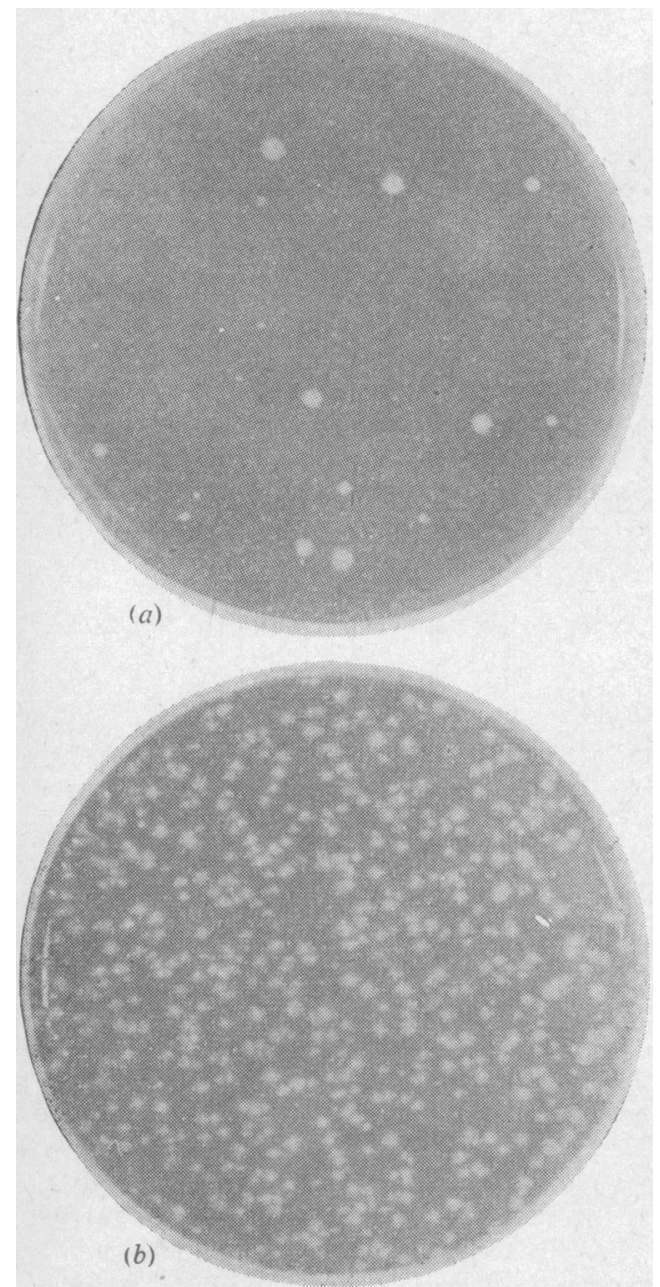

FIG. 2. - Twenty-minute exposure plates (blood-agar) taken $(a)$ before A.'s entry into room and (b) after A.'s dressing and undressing in room.

\section{Theatre Suite}

The theatre suite is modern, having been in use since November 1959. There is a plenum system of ventilation, with adiabatic cooling and humidification, which gives about 17 changes of air per hour in the theatres. Exposure plates placed at seven sites in the theatres and also swabs taken direct from six random sites showed the widespread presence of Staph.

TABLB II.-Sttes of Origin and Phage Types of Staph. aureus

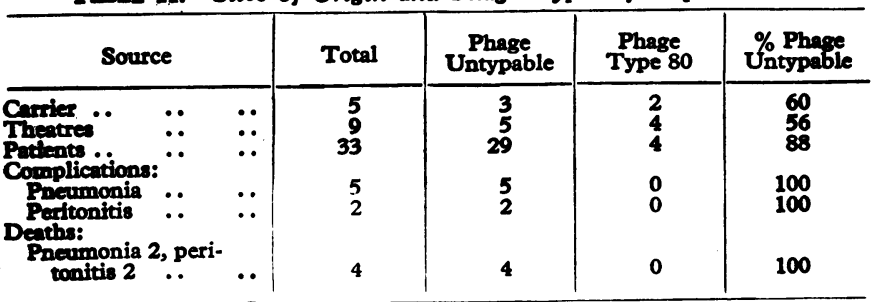

aureus. The total colony counts on these exposure plates varied from 10 to 28 colonies per plate per hour of exposure (mean 17 colonies per plate per hour) and a total of six colonies of Staph. aureus were isolated ( $5 \%$ of total colonies isolated). Staph. aureus was also isolated from swabs taken direct from three of the six random sites. These organisms were of the same antibiotic sensitivity patterns and same phage type as those isolated from the carrier (Table II). No staphylococci were isolated from the filters or air-ducts of the ventilating plant.

\section{Patients}

A total of 33 patients were involved in this outbreak; in all of them surgical wounds were the primary site of infection. Staph. aureus phage type 80 was isolated from wound swabs from 4 of the patients, while the phage-untypable strain was isolated from the other 29 patients' wound swabs (Table II). The patients' ages ranged from 8 months to 88 years; 15 were male and 18 female.

Patients in 11 wards and under the care of six surgeons were involved in this outbreak. The distribution of patients according to wards and to surgical teams is given in Tables III and IV respectively.

Table III.-Distribution of Patients with Staphylococcal Wound-sepsis by Wards

\begin{tabular}{|c|c|c|c|c|c|}
\hline \multicolumn{5}{|c|}{ Ward } & \multirow{2}{*}{$\begin{array}{c}\text { No. of Cases } \\
8 \\
6 \\
6 \\
3 \\
4 \\
6\end{array}$} \\
\hline $\begin{array}{l}\text { Male surgical } 1 \\
\text { Female " } 2 \\
\text { " } 2 \\
\text { Gynaecological } \\
6 \text { other wards (1 case }\end{array}$ & 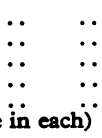 & $\begin{array}{l}\ldots \\
\cdots \\
\cdots \\
\cdots\end{array}$ & $\begin{array}{l}\ldots \\
\cdots \\
\cdots \\
\cdots\end{array}$ & $\begin{array}{l}\ldots \\
\because \\
\because \\
\cdots\end{array}$ & \\
\hline Total & .. & . & . & $\ldots$ & 33 \\
\hline
\end{tabular}

TaBle IV.-Distribution of 33 Patients with Staphylococcal Wound-

\begin{tabular}{|c|c|c|c|c|}
\hline Surgeon & \multicolumn{3}{|c|}{ Specialty } & No. of Cases \\
\hline \multirow{4}{*}{$\begin{array}{l}\mathbf{A} \\
\mathbf{B} \\
\mathbf{C} \\
\mathbf{D} \\
\mathbf{B} \\
\mathbf{F}\end{array}$} & General surgery & $\ldots$ & $\ldots$ & \multirow{4}{*}{$\begin{array}{r}11 \\
6 \\
6 \\
5 \\
3 \\
2\end{array}$} \\
\hline & Orthopaedics & $\begin{array}{ll}\cdots & \cdots\end{array}$ & $\because$. & \\
\hline & Obstetrics and gyna & aecology & .. & \\
\hline & $\begin{array}{l}\text { General surgery } \\
\text { ", }\end{array}$ & $\ddot{x}$ & $\ddot{.}$ & \\
\hline
\end{tabular}

All the patients were operated on in the theatres in the operating-suite described above during the period 9-28 January. Thirteen were operated on in theatre 1 and twenty in theatre 2. These details are summarized in Table V, together with the total number of operations performed in each theatre during the above period. Out of a total of 217 patients operated on 33 $(15.2 \%)$ developed staphylococcal wound infections.

Table V.-Distribution of Patients with Staphylococcal Wound-sepsis

\begin{tabular}{cc|c|c|c}
\multicolumn{1}{c|}{ by Operating-theatre } \\
\hline & & $\begin{array}{c}\text { No. of Infected } \\
\text { Cases }\end{array}$ & $\begin{array}{c}\text { Total No. } \\
\text { of Operations }\end{array}$ & $\begin{array}{c}\% \text { Wound } \\
\text { Infections }\end{array}$ \\
\hline $\begin{array}{ccc}\text { Theatre } \\
\text { 1 }\end{array}$ & $\cdots$ & 20 & 115 & 17.4 \\
\hline Total & $\cdots$ & 13 & 102 & 12.7 \\
\hline
\end{tabular}

The interval between the time of operation and of clinical presentation of wound infection ranged from 2 to 20 days (mean 9.6 days) (Fig. 3).

In Fig. 4 an attempt has been made to correlate the subsequent occurrence of wound sepsis in a patient with A.'s presence in the theatre at the time of the operation. Staphylococcal wound infections continued to occur for five days after A.'s last attendance in the theatre suite and for 10 days after his last known attendance in theatre 2 . 


\section{Complications}

In addition to wound sepsis and its surgical sequelae staphylococcal pneumonia occurred in five patients, and staphylococcal peritonitis in two. All of them were infected with the phage-untypable strain of Staph. aureus (Table II).

\section{Mortality}

In spite of intensive treatment there were 4 deaths among the 33 patients (mortality rate $12.1 \%$ ). These deaths occurred in patients in whom complications had developed-two had

\section{Discussion}

Different strains of Staph. aureus show wide variation in virulence (Barber, Dutton, Beard, Elmes, and Williams, 1960). In particular, phage type $80 / 81$, first isolated in Australia by Rountree and Freeman (1955) has subsequently been associated with severe outbreaks of staphylococcal infection throughout the world. More recently a newly recognized strain of Staph. aureus, designated phage type $\mathrm{A}$, has been associated with a series of severe staphylococcal outbreaks in six hospitals in the Glasgow area (Temple and Blackburn, 1963) and also in hospitals in the Leeds area (Jacobs et al., 1963). In the present outbreak, 4 cases were associated with phage type 80 infections
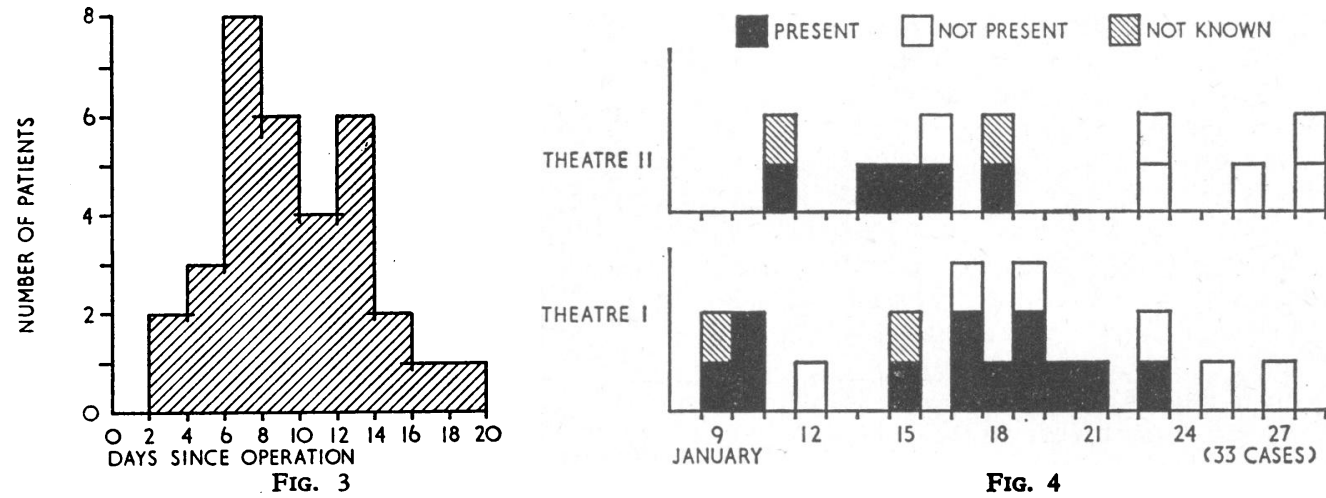

FIg. 3.- Time interval between operation and isolation of Staph. aureus from wound swabs. Fig. 4.-Retrospective analysis of the carrier's presence or absence in the theatre at time of operation.

developed pneumonia and two peritonitis, due in all cases to the phage-untypable strain of Staph. aureus (Table II).

\section{Management}

On 24 January it became apparent that the theatre suite was contaminated with Staph. aureus and that the most likely source of these organisms was the anaesthetist, A. At the time it was decided, firstly, to suspend A. from duty ; secondly, to close and cleanse the theatre suite (using another operating theatre for emergency surgery); thirdly, to suspend elective surgery ; and, fourthly, to regard any ward in which a patient had developed a staphylococcal wound infection as contaminated.

The theatre suite was closed on 24 January and washed down with 1:80 sodium hypochlorite solution. The theatres were reopened after 36 hours, but subsequently it was discovered that staphylococci were still present. The suite was therefore closed again, and every part (including ceilings, cupboards, and loose apparatus) was scrupulously washed with $1: 80$ sodium hypochlorite solution by hand, while all dressings and linen were laundered and autoclaved. Finally, the whole theatre suite was fumigated with formalin vapour produced from the Formitas outfit (Sanitas \& Co. Ltd.) and kept sealed for four hours ; during this procedure the ventilating plant was stopped. Twenty-four hours later no staphylococci were isolated on prolonged (12-hour) exposure plates or direct swabs taken at many sites in the theatres.

Because of the large number of patients affected in this outbreak, the normal facilities for isolation soon became inadequate. Therefore it was decided to segregate infected and non-infected patients in separate "dirty" and "clean" wards respectively. As soon as a patient was discharged from a " dirty" ward, his bedding and surrounding curtains were "formalin-stoved" and laundered. After the last patient had been discharged each "dirty" ward was cleaned in the same careful way as in the theatres on the second occasion (washing down with a $1: 80$ solution of sodium hypochlorite, followed by formalin fumigation). and 29 with the phage-untypable strain. This untypable strain was isolated from all the patients in whom staphylococcal pneumonia or peritonitis occurred. This may imply that the untypable strain was more virulent or more infective to patients than phage type 80 (it is of interest that the observed incidence of both strains in the theatre was almost equal). It is therefore felt that attention should be drawn to the occurrence of the outbreak, though it is impossible to foretell the future importance of this strain.

In the outbreak under review circumstantial evidence strongly suggests that the patients' wounds became infected in the theatre at the time of the operation. Other workers have also concluded that suppuration in surgical wounds is most likely to have arisen from infection in the theatre (Gillespie, Alder, Ayliffe, Bradbeer, and Wypkema, 1959 ; Howe and Marston, 1962). An anaesthetist (A.) appears to have been the source of staphylococcal contamination of the theatre suite. It is of interest to note that this individual had in the past been a nasal staphylococcal carrier, and had had psoriasis which remained quiescent until December 1962, when he suffered an acute exacerbation of his skin condition. However, at the time of his return to duty, in January 1963, his skin was desquamating over wide areas. The increased liability of patients with certain skin lesions to be disseminators of staphylococci has been demonstrated by Hare and Cooke (1961), while Davies and Noble (1962) have demonstrated the importance of desquamated skin-scales in the carriage of bacteria. It is possible that A. was transformed from a relatively harmless nasal carrier into a highly dangerous staphylococcal disseminator by the presence of desquamating psoriatic lesions colonized by staphylococci. In this context the part played by topical and systemic corticosteroid therapy on the change in A.'s skin : bacteria relationship remains unknown.

It was not possible to determine the aerial density of staphylococci in the theatre suite during this outbreak, but an impression of the numbers of organisms disseminated by $\mathrm{A}$. has been given in Fig. 2. Wound infections continued to develop in patients operated on during the five days after A.'s last attendance in the theatre suite, the most probable explanation being the continued survival of staphylococci in the theatres, for Noble 
(1962) has shown that these organisms can survive for up to seven days in ward air. Though it has been shown that efficient theatre ventilation will greatly reduce the concentration of airborne bacteria (Shooter and Williams, 1961) it is quite apparent that modern plenum ventilation was unable to prevent theatre infection in these circumstances.

Considerable doubt has been cast on the value of "routine" washing down of theatres with 1:80 sodium hypochlorite solution, since it has been shown that staphylococci survived this procedure during the first closure of the theatre suite. However, the combined use of the same strength of hypochlorite solution applied to literally every part of the theatre suite and its contents, followed by formalin fumigation, has been shown to have been effective, since staphylococci could no longer be isolated and no further wound infections occurred. It is not possible to define the relative importance of the thorough washing down with hypochlorite solution in relation to the importance of formalin fumigation. Hare, Raik, and Gash (1963) have, however, shown under experimental conditions that $1: 80$ sodium hypochlorite solution was highly efficient in killing Staph. aureus whereas formalin was much less effective. The dangers of relying on " routine" cleansing of contaminated theatres have been inadvertently demonstrated in this outbreak, and it is my view that such theatres must remain out of use until full bacteriological results are available.

The policy of segregation of patients into "clean" and "dirty" wards in an outbreak of this type appears to have been justified, since no obvious cases of cross-infection in the wards were detected. This, in addition, reflects great credit on the nursing staff.

Noble (1962) found six disseminators of staphylococci in 3,675 surgical patients. The incidence of disseminators among those working in operating-theatres is not known, but the outbreak under review emphasizes the grave hazards of the presence of such an individual in the theatre.

The Lancet (1963) stated: "Without dependable statistics it is impossible to assess the size of the staphylococcal problem or to determine the value of control measures. . . . The detection and recording of all infections, trivial and serious, the identification of important sources of cross-infection, the correlation of clinical and laboratory findings, and the supervision of special precautions all take more time than can be spared by busy doctors and nurses." From personal experience I would wholeheartedly support these views, for during this outbreak it was impossible to attend to any other duties or commitments. It is felt that the suggestion, made by Gardner, Stamp, Bowgen, and Moore (1962) and quoted in the same Lancet editorial, of overcoming these difficulties by appointing a full-time sister to work with the team in control of infection is one that should be carefully considered by many hospitals.

Considering this outbreak in retrospect it is felt that three points, which though obvious are nevertheless of fundamental importance, should be stressed: (1) the value of keeping a central register of all staphylococcal infections occurring in a hospital ; (2) the importance of the co-operation of the medical staff in formulating a comprehensive collective plan of action at the earliest possible stage; and (3) the importance of the co-operation of medical, nursing, and administrative staffs in rapidly implementing this plan.

\section{Summary}

A severe outbreak of staphylococcal infection involving 33 surgical patients in a general hospital is described.

Two strains of Staphylococcus aureus were involved: phage type 80 (4 cases, no deaths) and phage untypable $(77 \mathrm{w}(1,000$ R.T.D.)) (29 cases, 4 deaths).

An anaesthetist suffering from psoriasis was found to be carrying and disseminating staphylococci of these two strains, which were found to be widely distributed in two operatingtheatres.

The findings, and the management of the outbreak, are described and discussed.

ADDENDUM.-Since this paper was submitted for publication a similar but smaller outbreak of surgical wound infection has been reported by Ayliffe and Collins (G. A. J. Ayliffe and B. I. Collins, f. clin. Path., 1967, 20, 195). These infections were probably also acquired in the operating-theatre, from an orderly who had generalized dry eczema and who was both a nasal and skin carrier and a disseminator of another unusual strain of Staph. aureus.

I am greatly indebted to all who were involved in investigating and controlling this outbreak, whether medical, nursing, laboratory, or administrative staff. I also wish to thank Drs. Holt, Jacobs, and Willis for permission to quote the results of their investigations.

\section{REFERENCES}

Barber, M., Dutton, A. A. C., Beard, M. A., Elmes, P. C., and Williams, R. (1960) Brit med. f., 1, 11.

Davies, R. R., and Noble, W. C. (1962). Lancet, 2, 1295.

Gardner, A. M. N., Stamp, M., Bowgen, J. A., and Moore, B. (1962). Ibid., 2, 710.

Gillespie, W. A., Alder, V. G., Ayliffe, G. A. J., Bradbeer, J. W., and Wypkema, W. (1959). Ibid., 2, 781.

Hare, R., and Cooke, E. M. (1961). Brit. med. F., 2, 333.

- Raik, E., and Gash, S. (1963). Ibid., 1, 496.

Holt, H. D. (1963). Personal communication.

Howe, C. W., and Marston, A. T. (1962). Surg. Gynec. Obstet., 115, 266.

Jacobs, S. I., Willis, A. T., Ludlam, G. B.. and Goodburn, G. M. (1963). Lancet, 1, 972.

Lancet, 1963, 1, 537.

Noble, W. C. (1962). f. clin. Path., 15, 552.

Rountree, P. M., and Freeman, B. M. (1955). Med. F. Aust., 2, 157.

Shooter, R. A., and Williams, R. E. O. (1961). F. clin. Path., 14, 45.

Temple, N. E. I., and Blackburn, E. A. (1963). Lancet, 1, 581.

Willis, A. T. (1963). Personal communication. 